\title{
$\mathrm{MMB}$ 시험에 의한 평직 CFRP/GFRP 적층판 혼합모드 층간분리의 실험적 평가
}

\author{
곽정훈 · 강지웅 ${ }^{*}$ 권오헌 ${ }^{\dagger * *}$ \\ 부경대학교 대학원 - ${ }^{*}$ 대구한의대학교 보건학부 • ${ }^{* *}$ 부경대학교 안전공학과
}

(2013. 1. 11. 접수 / 2013. 7. 23. 채택)

\section{The Experimental Evaluation of the Mixed Mode Delamination in Woven CFRP/GFRP Laminates under MMB Test}

\author{
Jung-Hoon Kwak $\cdot$ Ji-Woong Kang ${ }^{*} \cdot$ Oh-Heon Kwon ${ }^{\dagger * *}$ \\ Graduate School, Pukyong National University \\ Faculty of Health, Daegu Haany University $\cdot{ }^{* *}$ Department of Safety Engineering, Pukyong National University \\ (Received January 11, 2013 / Accepted July 23, 2013)
}

\begin{abstract}
Blades of horizontal axis are nowadays made of composite materials. Generally, composite materials satisfy design provides lower weight and good stiffness, while laminate composites have often damages as like the delamination and cracks at the interface of laminates. The box spar and tail parts of a blade are composed of the CFRP/GFRP hybrid laminate composites. However, delamination and the interfacial crack often occur in the interface of CFRP/GFRP hybrid laminate composites under the mixed mode fracture condition, especially mode I and mode II. Therefore, there is a need for the evaluation of the mixed mode fracture behavior during the delamination of CFRP/GFRP hybrid laminates. This study shows the experimental results for the delamination fracture toughness in CFRP/GFRP hybrid laminate composites. Fracture toughness experiments and estimation are performed by using DMMB(Dissimilar mixed mode bending) specimen. The materials used in the test are a commercial woven type CFRP(Carbon fiber reinforced plastic) prepreg(CF3327) and UD type GFRP(Glass fiber reinforced plastic) prepreg(HD224A). A CFRP/GFRP hybrid laminate composite is composed by the 10 plies CFRP and GFRP prepreg for DMMB. A thickness of CFRP and GFRP layer is $2.5 \mathrm{~mm}$ and $3.0 \mathrm{~mm}$, respectively. Also the fulcrum location which is a loading parameter is changed from 80 to $100 \mathrm{~mm}$ on the specimen of length $120 \mathrm{~mm}$ because it defines the ratio of mode I to mode II. In this study, the effects of the fulcrum location are evaluated in the viewpoint of energy release rate in mode I and mode II contribution. The results show that the delamination crack initiates at higher displacement and lower load according to the increase of the fulcrum location ratio. And the variation of the energy release rate for mode I and II contributions for the mode mixity are shown.
\end{abstract}

Key Words : MMB(mixed mode bending), energy release rate, hybrid laminate, fulcrum location, mode mixity

\section{1. 서 론}

국내외에서 풍력발전기의 연구가 에너지 고갈 문제의 해 결방안으로 활발히 이루어지고 있다. 현재 $7 \mathrm{MW}$ 급까지 개 발됨에 따라 풍력터빈 블레이드 무게가 약 수 십 톤에 해 당할 정도로 대형화되고 전장도 길어지고 있어 발전효율에 영향을 미치고 있다. 따라서 블레이드 자중 등을 고려한 경 량화 문제가 대두되어, 대체재로 유리섬유(GFRP) 또는 탄 소섬유(CFRP)복합재를 적용하기 시작하였다. $\mathrm{CFRP}$ 의 적용 부는 제조상의 난점 및 경제성 등을 고려하여 외부하중을 주 로 부담하는 블레이드 박스 스파(Box spar)부에만 적용하여 주변의 GFRP부분과 하이브리드 적층이 되도록 하였다. 그러나 강풍, 난류 등 환경 급변화의 발생에 의하여 하이브 리드 적층부를 가지는 블레이드 박스 스파부에서의 적층분 리(delamination)현상 및 균열발생 등으로 블레이드의 수명
단축 등이 우려되어 강도향상 문제가 제기 될 수 있다 ${ }^{1)}$. 적층분리 현상에 대한 연구는 지금까지 많은 연구가 수행 되어져 오고 있다 ${ }^{2-5)}$. Ozdil 등 ${ }^{6}$ 은 일방향 유리/폴리에스터 프리프레그를 $0^{\circ}, 30^{\circ}, 45^{\circ}$ 로 적층한 복합재에 대하여 적층 분리 파괴인성치의 값을 구하였고, Bennati 등 ${ }^{7}$ 및 Hojo 등 ${ }^{8)}$ 은 섬유강화 에폭시 적층재에 대하여 $\mathrm{DCB}$ (Double Cantilever Bending)시험을 수행하여 모드 I 층간 파괴인성을 평 가하였다. 혼합모드 상태의 층간파괴분리에 대한 연구는 Soboyejo 등') 이 이종재료에서 계면파괴현상을 실험으로 평가하 였고, Marannano 등 ${ }^{10)}$ 은 직교이방성과 섬유-금속 하이브 리드 복합재료에 대하여 계면 적층분리기구를 조사하였다. 또한 Mollon 등 ${ }^{11)}$ 은 $\mathrm{MMB}$ 및 $\mathrm{ADCB}$ 시험편을 이용하여 $\mathrm{G}$ 와 $\mathrm{G}_{\mathrm{II}} / \mathrm{G}$ 의 관계를 연구하였다. 본 연구의 목적은 $\mathrm{CFRP} /$ $\mathrm{GFRP}$ 하이브리드 복합재료의 층간에 존재하는 균열에 의한 층간분리 에너지해방률이 $\mathrm{MMB}$ 시험의 하중지지점 위치 
에 따라 어떤 영향을 나타내는 지를 평가하는 것이다.

\section{2. 재료 및 실험방법}

\section{1. 시험편 및 재료}

$\mathrm{MMB}$ 혼합모드 파괴실험에 사용된 재료는 평직 탄소섬 유강화(plain woven carbon prepreg) 및 유리섬유강화 프리 프레그(glass fiber reinforced plastics prepreg)로 국내 한국 카본(주)에서 생산, 시판되는 CF3327EPC(두께: $0.27 \mathrm{~mm}$ )와 현대카본(주)의 $\mathrm{UD}$ 를 이용하였으며, $250 \mathrm{~mm} \times 250 \mathrm{~mm}$ 로 절단된 프리프레그는 평직 $\mathrm{CFRP}$ 와 GFRP를 각각 $10 \mathrm{ply}$ 씩 적층하여 최종 $20 \mathrm{ply}$ 로 적층하였다. $\mathrm{CFRP}$ 의 섬유방향은 $[0]_{10 \mathrm{~T}}$ 로 하였으며, $\mathrm{GFRP}$ 는 $[0]_{10 \mathrm{~T}}$ 일방향 적층하였다. 초 기균열 $\left(\mathrm{a}_{0}\right)$ 은 평직 $\mathrm{CFRP}[0]_{10 \mathrm{~T}}$ 와 $\mathrm{GFRP}[0]_{10 \mathrm{~T}}$ 사이에 $\mathrm{Te}-$ flon tape를 초기 노치 길이만큼 삽입하여 형성하였으며, 이후 최종 적층하여 $\left[0_{\mathrm{C}} / 0 \mathrm{~g}\right]_{20 \mathrm{~T}}$ 로 된 적층판을 구성하였다. 하이브리드 적층판의 두께는 CFRP적층이 $2.5 \mathrm{~mm}$, GFRP 적층이 $3 \mathrm{~mm}$ 로 가압되어 최종 $5.5 \mathrm{~mm}$ 로 성형되었다. 적 층판은 성형판에 실리콘 오일인 이형재(KS707)를 균일하 게 바른 후 열 성형기(Hot Press, 국내 $\mathrm{D}$ 사, $\left.500 \mathrm{~kg} / \mathrm{cm}^{2}\right)$ 를 이용하여 성형 온도와 게이지 압력을 각각 $130^{\circ} \mathrm{C}, 5.7 \mathrm{~kg} f$ $\mathrm{cm}^{2}$ 에서 60 분간 성형하였고 잔류응력 완화와 뒤틀림 및 변형을 방지하기 위하여 열 성형기 내에서 2시간 이상 냉 각한 후 자연공냉하였다. Table 1에는 CFRP와 GFRP적층판 의 각각의 기계적 물성치를 나타낸다.

성형된 $\mathrm{CFRP/GFRP} \mathrm{하이브리드} \mathrm{복합재료는} \mathrm{시험편} \mathrm{제}$ 작용 다이몬드 정밀 휠커터를 사용하여 $120 \mathrm{~mm} \times 22 \mathrm{~mm}$ 로 절단가공 하였으며, Fig. 1과 같이 자체 제작한 알루미늄 블록을 속건성 에폭시 수지인 아랄다이트(Araldite Rapid)

Table 1. Mechanical properties of CFRP and GFRP laminated composite.

\begin{tabular}{c|c|c|c}
\hline Mroperty & Unit & CFRP(woven) & GFRP(UD) \\
\hline \hline Elastic modulus, $\mathrm{E}$ & $\mathrm{GPa}$ & 54.3 & 43.3 \\
\hline Ultimate strength, $\sigma \mathrm{u}$ & $\mathrm{GPa}$ & 1.527 & 1.102 \\
\hline Poisson's ratio, $\nu$ & - & 0.1 & 0.31 \\
\hline Thickness, $\mathrm{t}$ & $\mathrm{mm}$ & 2.5 & 3 \\
\hline
\end{tabular}

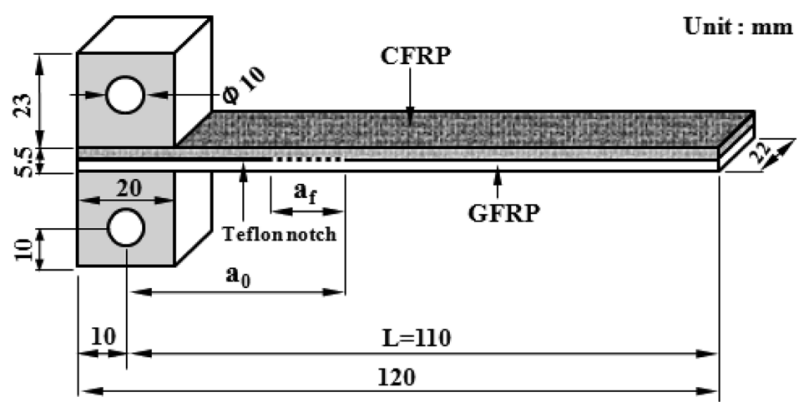

Fig. 1. Geometry of DMMB specimen.

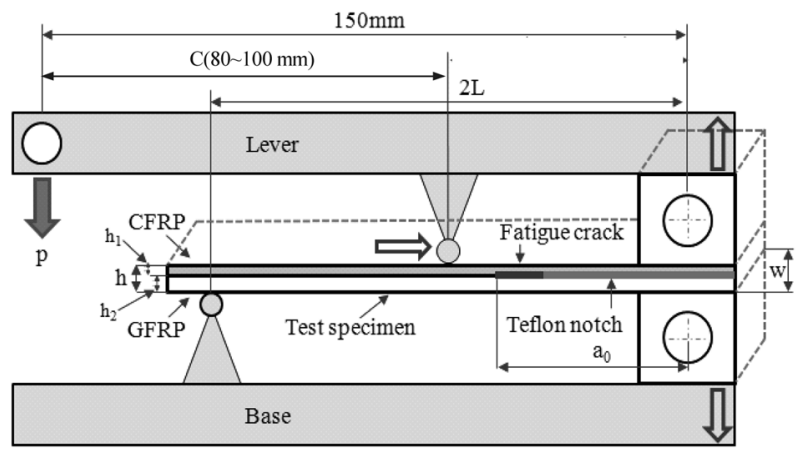

Fig. 2. A overview of MMB experimental apparatus.

Table 2. The codes of the several specimen type.

\begin{tabular}{|c|c|c|}
\hline Code $\quad$ Type & Laminate & Location(mm) \\
\hline L0a45C80 & {$\left[0_{\mathrm{C}} / 0_{\mathrm{g}}\right]_{20 \mathrm{~T}}$} & 80 \\
\hline L0a45C85 & {$\left[0_{\mathrm{C}} / 0_{\mathrm{g}}\right]_{20 \mathrm{~T}}$} & 85 \\
\hline L0a45C90 & {$\left[0_{\mathrm{C}} / 0_{\mathrm{g}}\right]_{20 \mathrm{~T}}$} & 90 \\
\hline L0a45C100 & {$\left[0_{\mathrm{C}} / 0_{\mathrm{g}}\right]_{20 \mathrm{~T}}$} & 100 \\
\hline
\end{tabular}

로 부착하였다. 또한 알루미늄 블록이 부착된 $\mathrm{MMB}$ 시험 편은 전기로에서 $100^{\circ} \mathrm{C}$ 로 30 분간 열처리를 수행하여 알 루미늄 블록의 접합강도를 강화시켜 시험도중 시험편에 서 알루미늄 블록이 탈락하는 것을 방지하였다.

\section{2. 실험방법}

제작된 $\mathrm{DMMB}$ 시험편에 $a_{0} / L=0.45$ 에 대응하는 초기 균열을 생성하기 위해서 teflon tape를 초기 노치 앞에 삽 입하고, 피로 예비 균열을 만능 동적시험기 $(\mathrm{H}$ 사, $50 \mathrm{kN})$ 를 이용하여 $K_{f}^{\max }$ 가 $0.16 \mathrm{MPa}$ 을 넘지 않는 범위에서 주파 수 $2 \mathrm{~Hz}$ 로 생성하였다. $\mathrm{MMB}$ 파괴 시험에 사용된 시험 기는 소형 인장시험기(Tinus Olsen, H5KS)를 사용하였으며, ASTM D 6671 ${ }^{12)}$ 에서 추천하고 있는 방법인 변위제어 0.2 $\mathrm{mm} / \mathrm{min}$ 로 행하여 졌다. 파괴시험 동안 균열 성장길이 측정은 실체 현미경(Kyowa, ×20)을 이동식 현미경(Japan, N.O.W사)에 조립하여 육안으로 측정하였다.

측정된 균열길이는 디지털 변화기 IT-005D(Japan, M사) 로 PC에 저장하였다. Fig. 2는 실험장치의 개략도를 나타 낸다. Table 2에는 4 가지 종류의 시험법에 부여된 식별자 를 나타낸다. 각각의 시험 조건에 대하여 하중매개변수인 지지점 (fulcrum location), c를 $80 \mathrm{~mm} 100 \mathrm{~mm}$ 사이에 4가 지로 변화시켜 실험하였다.

\section{3. 에너지 해방률 평가식}

본 연구에서 사용된 혼합모드 에너지 해방률 평가는 Williams $^{13)}$ 해석식을 기본으로 유도한 Marannano ${ }^{10)}$ 의 비 대칭 적층 분리와 하이브리드 직교이방성 적층판 적용식 (1), (2)를 사용한다. 
$G_{I}=\frac{6 P_{I}^{2}(a+\chi h)^{2}}{W^{2}}\left(\frac{1}{E_{11} h_{1}^{3}}+\frac{1}{E_{21} h_{2}^{3}}\right)$

$G_{I I}=\frac{6 P_{I I}^{2} a^{2}}{W^{2}} \gamma$

$\gamma=\frac{\alpha}{E_{11} h_{1}^{3}}+\frac{\beta}{E_{21} h_{2}^{3}}-\frac{1}{h^{2}\left(E_{11} h_{1}+E_{21} h_{2}\right)}$

여기서 $\alpha, \beta$ 는 적층판 각각(CFRP 및 $\mathrm{GFRP})$ 에 작용되는 모드 II하중 $\mathrm{P}_{\mathrm{II}}$ 의 부분력이다.

$\alpha=\frac{E_{11} h_{1}^{3}}{E_{11} h_{1}^{3}+E_{21} h_{2}^{3}}$

또 $\mathrm{P}_{\mathrm{I}}$ 은 모드 $\mathrm{I}$ 하중에 해당되며 $a, h_{1}, h_{2}, E_{11}, E_{21}$ 및 $\mathrm{W}$ 는 각각 균열길이, 적층판 두께, 탄성계수 및 폭을 나타낸다. $\chi$ 는 균열길이 수정계수이며 문헌(14)에서 얻어졌다.

\section{4. 결과 및 고찰}

\section{1. $\mathrm{DMMB}$ 시험편에 의한 파괴시험}

Fig. 3은 $\mathrm{DMMB}$ 시험편을 이용한 $\mathrm{MMB}$ 혼합모드 파괴 실험에서 얻어진 하중과 변위의 관계를 나타내고 있다. 하 중-변위곡선은 하중점 위치에 관계없이 초기균열이 진전 개시되는 지점까지 거의 선형적으로 증가하여 균열진전개 시와 더불어 감소하기 시작한다. 균열진전 개시 이전의 하 중선도의 기울기는 하중점 지지점이 길어질수록 더욱 더 급 격히 증가하는 경향을 나타낸다. 이후 균열이 성장함에 따 라 하중은 다소 증감을 나타내며 서서히 감소하지만 변위 가 약 $15 \mathrm{~mm}$ 이상이 됨에도 불구하고 급격한 하중의 변화 는 나타나지 않았다. 이와 같은 현상은 섬유복합재료의 일 반적인 형태로 간주할 수 있다.

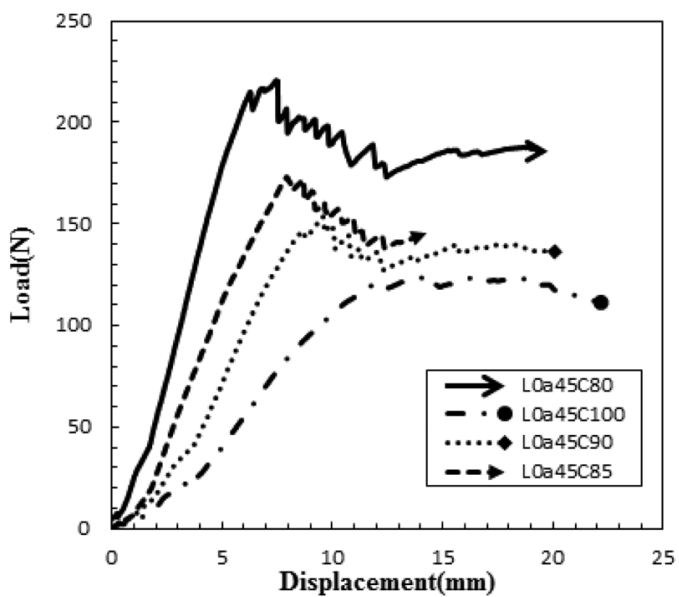

Fig. 3. The relationships of the load-displacement according to the fulcrum loading point under MMB test with mode $1+\|$.

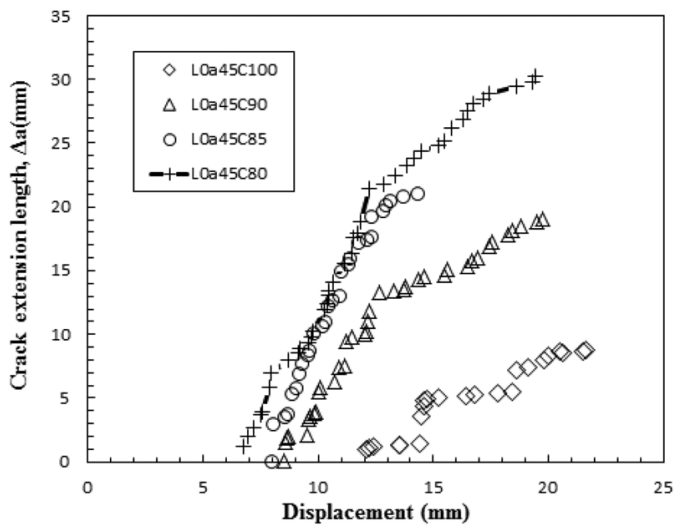

Fig. 4. The relationships of the crack extension length and displacement according to the fulcrum loading point under MMB test with mode $I+I I$.

Fig. 4는 하중변위에 대한 성장균열길이의 변화를 나타 내고 있다.

Fig. 4에서 알 수 있는 것처럼 균열개시는 하중지지점 위치에 따라 $\mathrm{c}=100 \mathrm{~mm}$ 의 경우는 변위가 약 $12 \mathrm{~mm}$ 에서 부터, $80 \mathrm{~mm}$ 의 경우는 약 $6.8 \mathrm{~mm}$ 에서부터 균열이 진전 하기 시작하여 실험 종료시까지 완만한 증가를 나타내었다. 최대 균열진전량은 $\mathrm{c}=80 \mathrm{~mm}$ 경우에 약 $35.2 \mathrm{~mm}$ 까지 측 정되었다.

또한 하중변위에 대한 균열성장속도율의 차이는 균열 성장이 비교적 선형적으로 증가하는 구간에서는 $\mathrm{c}=100 \mathrm{~mm}$ 의 경우를 제외하고 그다지 크게 나타나지 않았다.

\section{2. $\mathrm{MMB}$ 혼합모드 에너지해방률 평가}

$\mathrm{DMMB}$ 시험편에 의한 하이브리드 $\mathrm{CFRP} / \mathrm{GFRP}$ 복합재의 혼합모드 파괴인성치는 식 (1) (4)로 얻어지는 에너지해방 율 $\mathrm{G}$ 를 사용하여 평가하였다.

Fig. 5는 식 (1)을 사용하여 얻어진 모드 I 층간파괴 에

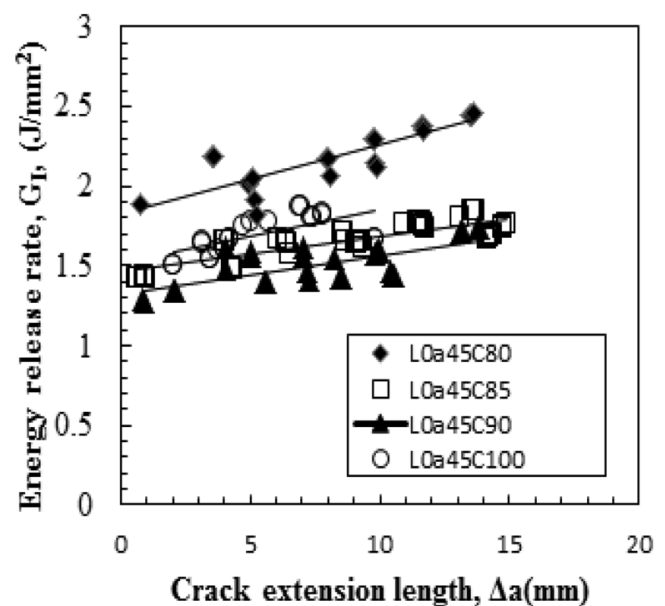

Fig. 5. The hybrid interlaminar fracture toughness by the energy release rate, $\mathrm{Gl}$. 
너지 해방률 $G_{I}$ 의 변화를 나타낸다.

최초 균열이 성장 개시하는 시점에서의 $G_{I C}$ 는 $\left[0_{\mathrm{C}} / 0 \mathrm{~g}\right]_{20 \mathrm{~T}}$ 의 경우, $\mathrm{c}=80,85,90$ 및 $100 \mathrm{~mm}$ 에서 각각 $1.823,1.459$, 1.314 및 $1.517 \mathrm{~J} / \mathrm{mm}^{2}$ 로 얻어졌으며, 하중지지점 $\mathrm{c}$ 가 커 질수록 모드 I 에너지해방률 파괴인성치는 감소하다가 $\mathrm{c}=$ $100 \mathrm{~mm}$ 에서 오히려 증가하였다. 한편 모든 경우에 있어서 균열이 진전함에 따라 파괴인성치는 전체적으로 상승경향을 나타내고 있고 $\mathrm{c}$ 값에 관계없이 거의 유사한 상승률을 보여 주고 있으나 $\mathrm{c}=80 \mathrm{~mm}$ 의 경우는 균열이 진전함에 따라 에너 지해방률의 모드 I 성분이 비교적 빠르게 커짐을 알 수 있다.

Fig. 6은 모드 혼합도 변화를 하중지지점 비에 따라 나 타내었다. 하중지지점 비가 길어질수록 혼합도는 5.45 $~$ $11.9^{\circ}$ 로 선형 증가함에 따라 에너지 해방률 파괴인성치값 들은 하중지지점 위치에 따라 Fig. 7과 같은 경향을 나타 냄을 알 수 있다.

Fig. 7은 파괴인성치로서의 에너지해방율 $\mathrm{G}$ 와 모드 혼 합도(mode mixity)와의 관계를 나타낸다. 모드 혼합도는 $\theta=\tan ^{-1} \sqrt{\frac{G_{I I c}}{G_{I c}}}$ 에 의하여 얻어졌으며 모드 혼합도 $\theta$ 가

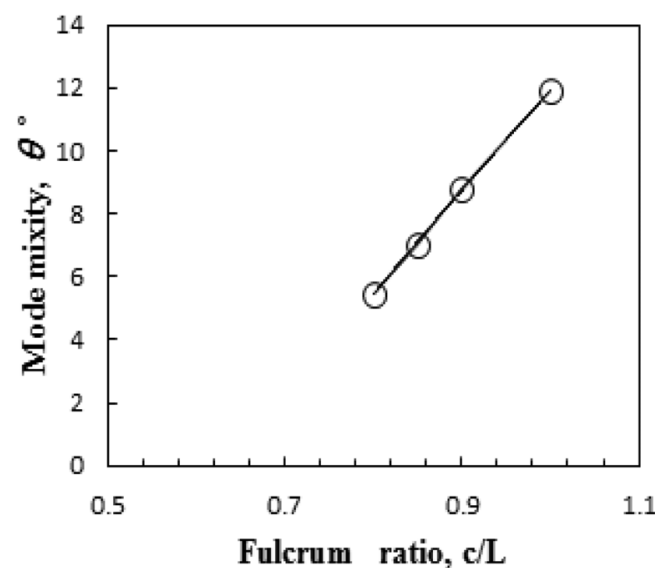

Fig. 6. The effect of the loading parameter, fulcrum ratio, for the mode mixity degree.

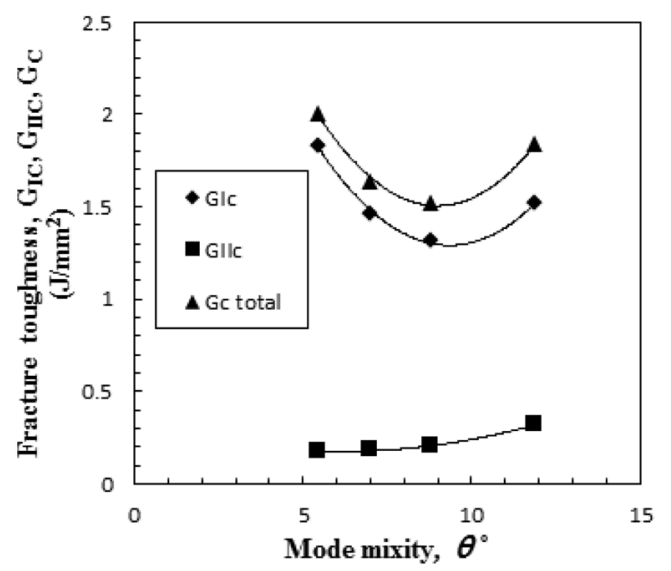

Fig. 7. The variation of the fracture toughness energy release rate curves according to the loading fulcrum ratio.
커질수록 모드 I 에너지해방률 파괴인성치는 감소하다가 증가하고 있다. 이러한 경향은 Soboyejo ${ }^{9)}$ 가 유한요소법으로 얻어진 결과와 유사하며, 전체 에너지해방률도 같은 경향을 나타내었다.

\section{3. 고찰}

하중-변위 관계에서 변위가 상당 구간 이상이 됨에도 불 구하고 급격한 하중의 변화는 나타나지 않았고 특히 CFRP/ GFRP 하이브리드 형태의 복합재료 상하 적층판의 상이한 특성에도 불구하고 계면에서의 적층분리에 의한 하중감 소량이 최소화되고 있는 것은 블레이드 경량화를 위한 CFRP/ GFRP 복합재의 유용성을 나타내고 있다. 한편 하중변위에 대한 균열성장속도율이 $\mathrm{c}=80 \sim 90 \mathrm{~mm}$ 의 경우는 3 4의 범 위에서 나타나 선형적으로 증가하는 구간에서는 그다지 차 이가 나타나지 않지만 $\mathrm{c}=100 \mathrm{~mm}$ 는 1.4 로 얻어져 균열성장 이 비교적 느리게 진행되었다. 이것은 균열단 근방에 접근 하게 되는 하중지지점 위치가 균열의 모드 I 성장을 억제 함으로써 발생되는 것으로 여겨진다. 따라서 모드 I 하중 성분이 커지게 되고 $\mathrm{c}=80 \mathrm{~mm}$ 경우의 파괴인성치는 균열이 진전함에 따라 모드 I 성분이 비교적 빠르게 커짐을 알 수 있다. 모드 II 에너지해방률 파괴인성치는 계속 증가하고 있 어 전단성분의 영향이 점점 커짐을 나타낸다. 현재의 하중 지지점 위치 범위내에서는 전체 에너지 해방률 파괴인성 치 중에서 모드 II 성분보다 모드 I 성분이 대부분을 차지하 고 있음을 알 수 있다.

그럼에도 불구하고 계면의 적층분리에 대한 전체 에너 지해방률은 모드 혼합도에 따라 증가하고 있다. 즉 하중 지지점 비의 증가에 따라 증가하고 있음을 알 수 있고 이 것은 증가된 모드 II 성분과 관련된 상부 적층판의 휨에 기인한 균열의 처짐에 의한 것으로 간주된다. 특히 하중지 지점 비 0.9 부터 증가율이 상승하여 적층분리에 대한 에너 지해방률에 미치는 영향이 커짐을 알 수 있다.

본 연구를 통해 얻어진 결과는 $\mathrm{CFRP/GFRP} \mathrm{하이브리드} \mathrm{적}$ 층 복합재료로 구성된 블레이드의 Box spar부에 대한 적층 분리 거동을 평가하는데 유용한 자료로 활용될 것으로 여 겨진다.

\section{4. 결 론}

$\mathrm{CFRP/GFRP} \mathrm{하이브리드} \mathrm{적층복합재에서} \mathrm{발생되는} \mathrm{혼합}$ 모드 적층파괴분리현상을 파악하기 위하여 $\mathrm{MMB}$ 시험을 수 행한 후 다음과 같은 결론을 얻었다.

1) $\mathrm{CFRP/GFRP} \mathrm{하이브리드} \mathrm{계면에서의} \mathrm{적층분리에} \mathrm{의한}$ 하중감소량이 최소화되어 블레이드 경량화에 유용성을 나 타내었다.

2) 하중변위에 대한 균열성장속도율의 차이는 균열성장 이 비교적 선형적으로 증가하는 구간에서는 그다지 크게 나타나지 않았다.

3) $G_{I C}$ 는 c $=80,85,90$ 및 $100 \mathrm{~mm}$ 에서 각각 $1.823,1.459$, 1.314 및 $1.517 \mathrm{~J} / \mathrm{mm}^{2}$ 로 얻어졌다. 
4) 하중지지점 c가 커질수록 모드 I 에너지해방률 파괴 인성치는 감소하다가 $\mathrm{c}=100 \mathrm{~mm}$ 에서 오히려 증가하였다.

감사의 글: 이 논문은 2011학년도 부경대학교의 지원을 받아 수행된 연구임(PK-2011-2-28).

\section{References}

1) D. Craig, "Wind Farms Information Forum", Wind Turbine Accident Data, 2005.

2) L. Banks-Sills, N. Travitzky and D. Ashkenazi, "Interface Fracture Properties of a Bimaterial Ceramic Composite", Mechanical Materials, Vol. 32, pp. 711 722, 2000.

3) A. Kuhl and J. Qu, "A Technique to Measure Interfacial Toughness Over a Range of Phase Angles", Journal of Electron Package, Vol. 122, pp. 147 151, 2000.

4) J. A. Wang, I. Wright, M. Lance and K. Liu, "A New Approach for Evaluating Thin Film Interface Fracture Toughness", Material Science Engineering A, Vol. 426, pp. 332 345, 2006.

5) A. Jyoti, R. Gibson and G. M. Newaz, "Experimental Studies of Mode I Energy Release Rate in Adhesively Bonded Width Tapered Composite DCB Specimens", Composites Science and Technology, Vol. 65, pp. 9 18, 2005.

6) F. Ozdil and L. A. Carlsson, "Beam Analysis of Angle-ply Laminate DCB Specimen", Composites Science and technology, Vol. 59, No. 2, pp. 305 315, 1999.

7) S. Bennati, M. Colleluori, D. Corigliano and P. S. Valvo, "An Enhanced Beam Theory Model of the Assymmetric Double Cantilever Beam Test for Composite Laminates", Composite
Science and Technology, Vol. 69, pp. 1735 1745, 2009.

8) M. Hojo, K. Kageyama and K. Tanaka, "Prestandardization Study on Mode I Interlaminar Fracture Toughness Test for CFRP in Japan”, Composites Science and Technology, Vol. 26, pp. 243 255, 1995.

9) W. O. Soboyejo, G. Y. Lu, S. Chengalva, J. Zhang and V. Kenner, "A Modified Mixed-mode Bending Specimen for the Interfacial Fracture Testing of Dissimilar Materials", Fatigue Fracture Engineering Materials Structure, Vol. 22, pp. 799 810, 1999.

10) G. V. Marannano and A. Pasta, "An Analysis of Interface Delamination Mechanism in Orthotropic and Hybrid Fiber Metal Composite Laminates", Engineering Fracture Mechanics, Vol. 74, pp. 612 626, 2007.

11) V. Mollon, J. Bonhomme, J. Vina, A. Arguells, "Mixed Mode Fracture Toughness:An Empirical Formulation for GI/GII Determination in Asymmetric DCB Specimens", Engineering Structures, Vol. 32, pp. 3699 3703, 2010.

12) Standard Test Method for Mixed Mode I-Mode II Interlaminar Fracture Toughness of Unidirectional Fiber Reinforced Polymer Matrix Composites, ASTM D6671M-06, ASTM Annual Book of Standards, 2006.

13) J. G. Walliams, "On the Calculation of Energy Rates for Cracked Laminates”, Kluwer Academic Publishers, 1987.

14) F. Ducept, D. Gamby and P. Davies, "A Mixed Mode Failure Criterion Derived from Tests on Symmetric and Asymmetric Specimens", Composite Science Technology, Vol. 59, pp. 609 619, 1999. 